\title{
AVALIAÇÃO DA CURVA EPIDÊMICA DOS CASOS DE DENGUE ENTRE 2009 E 2013 NO MUNICÍPIO DE FRANCO DA ROCHA, SÃO PAULO
}

\author{
EVALUATION OF EPIDEMIC CURVE OF DENGUE CASES BETWEEN 2009 AND \\ 2013 IN THE MUNICIPALITY OF FRANCO DA ROCHA, SAO PAULO
}

E. M. N. PAULA ${ }^{1 *}$, C. A. CRUZ ${ }^{2}$, C. S. L. NOGUEIRA ${ }^{2}$, R. B. MEIRELLES-BARTOLI ${ }^{1}$, A. A. B. CARVALHO ${ }^{2}$

\section{RESUMO}

A dengue, causada por um vírus da família Flaviviridae, tem apresentação clínica que pode variar de forma branda a um quadro grave, podendo evoluir ao óbito do paciente. A situação em Franco da Rocha não é muito diferente da dos demais municípios do Estado de São Paulo, em que o número de casos de dengue é crescente. Diante do exposto, teve-se como objetivo realizar um estudo sobre a situação epidemiológica da doença, avaliando casos notificados, por meio de métodos estatísticos. Este é um estudo retrospectivo analítico, sendo utilizada a variável distribuição da doença. Utilizaram-se dados secundários, referentes ao período de 2009 a 2013, retirados do site do Centro de Vigilância Epidemiológica, contendo informações sobre número de casos autóctones e importados. Os dados foram organizados em tabelas e gráficos. Buscou-se analisar o nível endêmico entre os anos de 2009 e 2012 e comparar com o ano de 2013 a ocorrência dessa enfermidade na cidade de Franco da Rocha, por meio dos métodos dos quartis e do nível endêmico. No período de 2009 e 2013 foram notificados, nesse município, 369 casos. Desse total, 58,58\% (222/369) ocorreram em 2012 e 13,19\% no ano de 2010. De forma geral, durante todos os anos, os primeiros seis meses destacaram-se por serem mais representativos quando comparados com os demais. O número de notificações de casos da doença começa a aumentar em janeiro, atinge um pico no mês de março e é decrescente nos meses seguintes, porém sempre em situação epidêmica. Com base na série histórica da doença nesse local, é possível inferir que em 2013 houve uma epidemia. O controle da dengue deve ser estabelecido com base em estudos como este, sendo possível, assim, o aprimoramento da vigilância epidemiológica com consequente redução da letalidade dessa enfermidade.

PALAVRAS-CHAVE: SAÚDE. VIGILÂNCIA EPIDEMIOLÓGICA. FLAVIVÍRUS.

ÁREA TEMÁTICA: Saúde Pública

\footnotetext{
${ }^{1}$ Universidade Federal de Goiás (UFG), Regional Jataí, Unidade Jatobá, Laboratório de Sanidade Animal ${ }^{2}$ Faculdade de Ciências Agrárias e Veterinárias da Universidade Estadual Paulista (UNESP) - Câmpus de Jaboticabal

* eric.gyn@gmail.com
} 